\title{
Methods in Six Sigma Quality and the Application of this Concept in Medical Sciences and Neurosciences and Other Branches of Medical Institution and Health Care System
}

\author{
PK Upadhyay ${ }^{1 *}$, G Tiwary ${ }^{2}$, K Upadhyay ${ }^{3}$ and U Kartikeya ${ }^{3}$ \\ ${ }^{1}$ Head of Neurosurgery and Associate Professor and Communicating Author, India \\ ${ }^{2}$ Director of Diagnostic Services, India \\ ${ }^{3} \mathrm{MBBS}$ Fellows, India \\ *Corresponding Author: PK Upadhyay, Head of Neurosurgery and Associate \\ Professor and Communicating Author, India.
}

Received: May 28, 2021

Published: July 08, 2021

(C) All rights are reserved by PK Upadhyay., et al.

\begin{abstract}
The concept of quality is as old as mankind [1,2]. Application of such concept in health care system was adopted in $18^{\text {th }}$ and mainly $19^{\text {th }}$ century $[3,4]$. Application of concept of six sigma to health care is one of the most modern of them. The application of this concept in medical and surgical sciences in Health care system is described to achieve optimal and up-to-date health care system.

Keywords: Healthcare System; Six Sigma; Medical Science; Neuroscience; Champion; Belt; Black Belt; Brown Belt; Green Belt; Master Belt; DMAIC Method; DMADV Methods
\end{abstract}

\section{Introduction}

Six sigma is a modern concept of quality in manufacturing and elsewhere applicable to quality management in healthcare as well.

Six sigma can be modelled as a business improvement approach. This process tries to find out and rules out causes of defects and errors in manufacturing and service process by concentrating on outputs that are vital to consumer and a clear financial return for the organization.

Here we will also discuss concept of lean management in health care and how can it help the healthcare system to achieve quality and other goals.

The six-sigma concept is based on statistical derivative that equates to 3.4 or even fewer errors or defect per million opportunities.

Six sigma is a broader philosophy and deployment approach where ultimate goal is that all the organization's critical process is at a six sigma level of potentiality.
Six sigma is a data driven approach and disciplined methodology for reducing defect in any process, from manufacturing to transactional and from product to service.

In health industry, defect and mistakes are not and cannot be tolerated. An error can cost a patient life or severely damage him. This means processes need to be in place and managed properly to eliminate mistakes $[5,6]$.

Managing the process needs timely data and predetermined answer to that timely data.

Six sigma is a prerequisite in a healthcare organization for employees dealing with critical patient information.

Timely data is the information that is already available or is very easily determined.

Six sigma can be enforced in individual departments.

Motorola in USA developed six sigma in 1981 as a business management strategy. 
Since 2010 it enjoys extensive application in many sectors of industry but not without any arguments.

Consumer anticipates one defect in a thousand try. On normal distribution that corresponds to three standard deviations, which is commonly stated as three sigma.

That's three-sigma expectation by consumer then how about six sigma? Instead of one failure per thousand how about 3.4 failure per ten thousand or one million? This is an outrageous change in performance. Motorola committed to it and reached their consumer's expectation. Later Motorola set even higher goals and continued improving processes every year.

Motorola also set challenging goals in reducing "cycle time" that is time taken to convert raw materials into a finished product.

Doing things right the first time saves rework, in turn saves time [7].

Saving time is key to the productivity ${ }^{8}$. Eliminating underperforming component from the system improves the productivity. Indeed, this can be applied to health industry as well and indeed the thrust of six sigma in health care is exactly to improve the productivity in health care while promoting patient safety and patient service.

\section{Materials and Methods}

In every organization there are decision makers who lead the six sigma methodology at the time of project. They are known as Champions. It's their responsibility to choose the project and then to find out the objectives achieved out of the project. To obtain these goals, the champion selects and mentor six sigma project leaders, who are known as the Belt.

There are three major level of Belts. Six sigma award specially trained person with recognition in form of belts.

The training is done in form of theory and execution (practical) of projects.

There are different kinds of Belt at project levels like Black belt, master black belt, green belt, yellow belt, and white belts.

- White belt: They are the beginners.

- Brown belt: Theory done but has no practical training or experience.
They are non-rankers.

The rankers are:

- $\quad$ Green belt: The theory and practical qualified practitioners certified to "carry out" six sigma projects are called green belts.

- $\quad$ Black belts: These are the practitioners certified to "Design and supervise" six sigma projects, called black belts.

- Master black belt: They are the practitioners certified "to train others and to supervise large and multiple projects", called Master black belt.

There is no accreditation board for the six sigma schools.

\section{Functions of six sigma in health care}

The health care organization adopt six sigma for following reasons. To improve patient satisfaction:

- The essence of six sigma in health care is to measure and eliminates errors in health care services.

- While some organization use six sigma to increase efficiency, the most successful organization rely on six sigma to reduce consumer complaints.

To standardize organization development:

- The organization who use six sigma can use two strategy to implement it.

- When the aim of six sigma is to overhaul an existing product or service, leader can use the "DMAIC" method. That is the workers participating in this method, Define, Measure, analyse, Improve and control their results.

- When the aim is to develop entirely new product. The participants use "DMADV" method. That is Defining, Measuring, analysing, defining and verifying their plans.

To coordinate metrics and competitors:

- Six sigma companies established for quality management measures its own method. Many organizations use six sigma to interact more directly with the competitors.

- $\quad$ For example, if two companies who relies on patient feedback can be addressed by a unified approach by two companies together. 
To ensure Industry and Governmental compliance:

- $\quad$ The six sigma involves reducing errors rate below 3.4 per million.

- $\quad$ By implementing six sigma strategy, organization win or maintain patient and employee satisfaction.

Benefits of six sigma:

- $\quad$ Six sigma is influences by consumer so as to achieve maximum patient satisfaction and minimum errors.

- Implementation of six sigma leads to increase in profits and decrease in costs. Thus, leading to good financial results.

- Six sigma targets on processes which should not vary but focuses on process improvement rather than final outcome.

- It focusses on prevention rather than fixing it. (Prevention is better than cure).

Thus, it focusses on problem and not on symptoms:

- This involves whole organizational processes and training. Here top down approach ensures every good thing is capitalized and every bad thing is quickly removed [9].

\section{Conclusion}

Six sigma is presently one of the best management system to achieve and continue to maintain achieved goals to the highest levels in health care system. It is one of most modern quality and standard achievement method and concept in medical institutions at present.

\section{Declaration}

No financial help has been taken from any financial institutions, companies. There is no conflict of interests.

\section{Bibliography}

1. Upadhyay PK and Tiwary G. "Concept of Quality services in Medical Science with special assurance to Super specialty surgical practice". Medical Science 11.41 (2014): 24-30.

2. Tiwary G and Upadhyay PK. "Safe conduct of medical or surgical procedures including neurosurgical procedures and special operating procedures (SOP)". Medical Science 11.41 (2014): 31-36.

3. Upadhyay PK and Tiwary G. "Standard of operation theatres (OT)/Procedural rooms". Medical Science 1.41 (2014): 37-42.
4. P K Upadhyay., et al. "Quality assurance in neurosciences and suitable standards for Neurosurgical operation theatre and procedural rooms". 1.1 (2018): 180002.

5. PK Upadhyay., et al. "Text Book of Quality assurance and Standards in Neuro and medical sciences". Smash world, USA (2019).

6. P K Upadhyay. "Text book of quality assurance and standards in Neurosurgery and surgical sciences". (2020).

7. PK Upadhyay., et al. "Text Book of Quality assurance and Standards in Neuro and medical sciences". Dr P.K. Upadhyay, Tiwary G, Kritika, Kartikeya; Smash world, USA, 2nd edition (2020).

8. Upadhyay PK., et al. "Quality Medical Service for Quality Assurance in Neurosciences and Medical Sciences Using International Standard Organization, Quality Standards and Concepts of Total Quality management (TQM)". Acta Scientific Medical Sciences 4.12 (2020).

9. Upadhyay PK., et al. "Methods to provide quality assurance in Medical Science and Neuroscience using International Standard Organization, Quality Standards and concepts of Total Quality management (TQM)". 3.1 (2020): 180017.

\section{Volume 5 Issue 8 August 2021}

(C) All rights are reserved by PK Upadhyay., et al. 